\title{
Crust Thickness Controlled Redox Conditions and the Origin of Calc- Alkaline Series in Arc Magmas
}

\author{
PÉTER LUFFI ${ }^{1,2}$ \\ ${ }^{1}$ Institute of Geodynamics, Romanian Academy, Bucharest, \\ Romania \\ ${ }^{2}$ Geological Institute of Romania, Bucharest, Romania \\ peter.luffi@gmail.com
}

Tholeiitic (TH) and calc-alkaline (CA) series are defined by the behavior of iron during magma crystallization. In volcanic arcs, they are largely controlled by $\mathrm{H}_{2} \mathrm{O}$ and oxygen fugacity $\left(f \mathrm{O}_{2}\right)$. Fe-enrichment trends defining $\mathrm{TH}$ series are widely acknowledged as requiring both anhydrous and reducing conditions. In contrast, the relative contribution of $\mathrm{H}_{2} \mathrm{O}$ and $f \mathrm{O}_{2}$ to the development of Fe-depletion trends characterizing the $\mathrm{CA}$ series is debated. Here, integrated experimental data are employed to demonstrate that magnetite fractionation is the main factor controlling Fe-depletion in arc magmas, and it is shown that $\mathrm{MgO}$ and $\mathrm{FeO}$ coordinates of the point where this mineral overtakes control on the behavior of iron along a liquid line of descent, the tipping point, contains valuable information about the hydration and redox conditions controlling the behavior of iron in crystallizing melts. Then, in order to assess how $\mathrm{H}_{2} \mathrm{O}$ and $f \mathrm{O}_{2}$ influence the tipping point's coordinates and the behavior of iron during magma crystallization, a thermodynamically underpinned quantitative model is calibrated. Results show that, while high $\mathrm{H}_{2} \mathrm{O}$ concentration is essential in limiting the productivity of plagioclase responsible for the $\mathrm{Fe}$ enrichment characterizing TH series, elevated $f \mathrm{O}_{2}$ controlling the fractionation of magnetite is crucial in developing CA trends. A global survey of modern subduction zone volcanism relying on the calibrated model indicates that the redox state of arc magmas, alike their CA affinity, correlates with crust thickness. Efficient Fe-depletion in crystallizing magmas is promoted by redox buffering; hence, the commonly observed oxidized nature of CA arc volcanics, unlike their volatile content, does not reflect conditions of their mantle source or the subducted slab, but must be set during crystallization in crustal magma chambers. Arc magmas differentiating in thicker crust tend to display a more pronounced CA affinity possibly because here magnetite fractionation is facilitated by a more oxidized environment. High- $f \mathrm{O}_{2}$ buffering may result from progressive assimilation of oxidized sulfur species that are more abundant at mature continental margins. Such a scenario is consistent with the global co-variation of iron and sulfur observed in arc volcanics worldwide. 